\title{
KARAKTERISTIK BATU KAPUR DALAM NEGERI UNTUK BAHAN BAKU PENDUKUNG PENGOLAHAN BIJIH BESI/BAJA
}

\author{
Wahyu Garinas \\ Peneliti Pusat Teknologi Pengembangan Sumberdaya Mineral-BPPT \\ Pusat Teknologi Pengembangan Sumberdaya Mineral (PTPSM) -TPSA \\ Badan Pengkajian dan Penerapan Teknologi (BPPT) \\ Gedung 820 Geostek Puspiptek, Serpong, Tangerang Selatan \\ Email: wahyu.garinas@bppt.go.id ; garinas64@gmail.com
}

\begin{abstract}
ABSTRAK
Batu kapur merupakan bahan penting yang digunakan sebagai bahan campuran di industri pengolahan bijih besi. Penelitian ini dilakukan untuk mengetahui informasi tentang karakteristik batu kapur dalam negeri yang melimpah sehingga dapat digunakan untuk bahan campuran di industri pengolahan bijih besi. Untuk mengetahui kemurnian batu kapur maka menggunakan standar BGS dan untuk mengetahui karakteristiknya untuk industri logam maka menggunakan standar literature dari industry logam dalam negeri, India dan ESDM. Kemurnian batu kapur menurut standar BGS maka sampel dari Sumatera, Jawa, Kalimantan dan Sulawesi umumnya sampel batu kapur menengah sampai tinggi (medium - high purity). Berdasarkan standar : industri logam (besi), Industri di India dan literatur ESDM maka sampel dari jawa barat, jawa tengah dan sumatera utara dapat digunakan sebagai bahan campuran pada industri logam (besi). Umumnya sampel Batu kapur dapat dipakai sebagai bahan baku campuran karena murni dan untuk memenuhi standar industri diperlukan proses pengolahan.
\end{abstract}

Kata kunci : Batu kapur, pengujian, standar, karakteristik batu kapur.

\begin{abstract}
This research was conducted to find out information about the characteristics of domestic limestone. Limestone is an important material used as a mixture in iron ore processing industries. To find out the purity of limestone and to determine its characteristics for the metal industry using the BGS standard. To find out its characteristics for the metal industry, it uses literature standards from the domestic metal industry, India and ESDM (minister of energy and mineral resources). According to BGS standards : The purity of limestone from Sumatra, Java, Kalimantan and Sulawesi is generally medium to high purity. Based on standards: metal (iron) industry, Indian industry and ESDM literature: samples from West Java, Central Java and North Sumatra be used as a mixture in the metal (iron) industry. Generally, limestone samples can be used as raw materials because they are pure and to meet industry standards, processing is required.
\end{abstract}

Key word : Limestone, testing, standard, limestone characteristic.

\section{A. PENDAHULUAN}

Di Indonesia, batu gamping sering disebut juga dengan istilah batu kapur, sedangkan istilah luarnya biasa disebut "limestone". Batu gamping paling sering terbentuk di perairan laut dangkal. Batu gamping (batu kapur) kebanyakan merupakan batuan sedimen organik yang terbentuk dari akumulasi cangkang, karang, alga, dan pecahan-pecahan sisa organisme. Batu gamping juga dapat 
menjadi batuan sedimen kimia yang terbentuk oleh pengendapan kalsium karbonat dari air danau ataupun air laut.

Dengan meningkatnya perkembangan teknologi maka sebagai pijakan awal perlu diketahui karakterisasi batuan kapur $\left(\mathrm{CaCO}_{3}\right)$ ini secara lebih mendalam. Hal ini sangat diperlukan guna sebagai informasi awal pengembangan batu kapur $\left(\mathrm{CaCO}_{3}\right)$ ke arah yang lebih luas lagi. Guna menjawab kebutuhan tersebut maka penelitian ini ditujukan untuk mengetahui informasi yang lebih mendalam mengenai karakteristik maupun kemurnian dari batu kapur $\left(\mathrm{CaCO}_{3}\right)$.

Batu kapur saat ini banyak dimanfaatkan sebagai bahan campuran pada industri besar misalnya untuk pembuatan semen dan industri lainnya seperti kapur pertanian, bahan campuran bangunan, bahan baku industri karet, industri kertas, industri logam dan industri lainnya. Pemanfaatan batu kapur umumnya dapat digunakan untuk perbaikan jalan, bahan pondasi untuk bangunan, sebagai bahan imbuhan pada air untuk di lokasi industri maupun rumah tangga dan untuk bahan campuran pada industri manufaktur baja, metalurgi dan industri lainnya seperti pabrik gula. Tumbuhnya industri pabrikan besi dan metalurgi pada saat ini yang menggunakan batu kapur untuk proses pembuatannya tentunya akan meningkatan kebutuhan batu kapur. Di industri baja dengan peryaratan tertentu diharuskan memenuhi standar untuk industri. Seperti diketahui banyak potensi dan industri kapur dalam negeri akan tetapi umumnya digunakan untuk bahan baku industri semen dan lainnya. Untuk industri pabrikan baja dan metalurgi yang ada umumnya membutuhkan batu kapur dengan persyaratan berbeda dengan lainnya. Untuk menunjang informasi tentang karakteristik atau kualitas batu kapur yang dipakai pada industri baja dan metalurgi maka dilakukan penelitian ini. Pada tahapan awal ini dilakukan identifikasi untuk kualitas daerah batu kapur yang tersebar diberbagai pulau besar di Indonesia dan kualitas batu kapur yang ada dibandingkan dengan standar pabrikan. Untuk mengetahui karakteristik sampel dibandingkan klasifikasi kemurnian batu kapur uji digunakan standar dari British Geological Survey (BGS). Untuk mengetahui karakteristik(kualitas) batu kapur untuk bahan campuran pada industri pengolahan besi maka digunakan standar : pabrik pengolahan besi baja dalam negeri, standar literatur dari kementerian ESDM dan standar dari India.

Dari hasil identifikasi bahan baku sampel dalam negeri yang ada maka dapat diketahui karakteristik batu kapur yang diuji belum semua memenuhi seluruhnya sesuai kebutuhan standar yang ada sehingga untuk penggunaannya selanjutnya tentu perlu proses untuk perbaikan kualitasnya agar dapat digunakan oleh industri logam dan metalurgi lainnya.

\section{Tujuan Penelitian}

Tujuan dari penelitian ini adalah untuk mengetahui karakteristik terutama kualitas batu kapur dari dalam negeri sebagai bahan baku pendukung pada industri manufaktur besi/baja. Sehingga bahan baku dalam negeri yang potensinya besar dapat dimanfaatkan secara optimal oleh industri besi/baja.

\section{B. BAHAN DAN METODE PENELITIAN}

Batu kapur dapat langsung dipakai sebagai bahan baku, misal pada industri semen, fondasi jalan, rumah dan sebagainya. Untuk produk pabrik diperlukan pengolahan terlebih dahulu, misal dengan pembakaran. Cara ini dimaksudkan untuk memperoleh kapur tohor $(\mathrm{CaO})$, kalsium hidroksida $\left(\mathrm{Ca}(\mathrm{OH})_{2}\right)$ dan gas $\mathrm{CO}_{2}$. Dalam peleburan dan pemurnian besi atau logam lainnya, batu gamping/ dolomit berfungsi sebagai imbuh pada tanur tinggi. Bijih besi mengandung silika dan alumina sebagai unsur tambahan serta dalam proses peleburan unsur-unsur tersebut bersenyawa dengan bahan pengimbuh berupa terak cair (seng) yang mengapung di atas lelehan besi, sehingga mudah dipisahkan. Disamping itu, $\mathrm{CaO}$ dalam batu gamping harus berkadar tinggi, hal itu diperlukan untuk mengikat gas-gas seperti $\mathrm{SO}_{2}$ dan $\mathrm{H}_{2} \mathrm{~S}$. Pemanfaatan umum batu kapur dan proses pengolahan serta jenis yang dibutuhkan oleh industri (Gambar 1). 
Bahan kapur yang diuji dalam penelitian ini adalah bahan baku yang didapatkan dari lapangan belum ada proses pemurnian dan sampel yang ada diuji sesuai dengan prosedur di laboratorium.

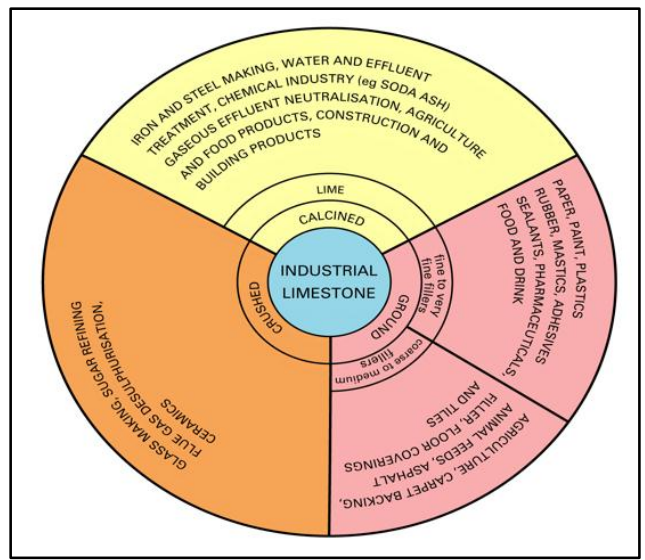

Gambar 1. Penggunaan Batu Kapur di Industri (sumber : BGS)

\section{B.1. Metode Penelitian}

Batu kapur digunakan sebagai bahan campuran yang ditambahkan pada bahan industri baja sehingga dapat meningkatkan sifat-sifatnya dan kemampuan pemprosesan. Batu kapur berfungsi sebagai fluks, yaitu untuk mengikat pengotor yang bersifat asam, seperti $\mathrm{SiO} 2$ yang membentuk terak. Dalam penelitian ini metode yang dilakukan antara lain :

1. Pengumpulam data primer meliputi : uji terhadap sampel uji dari beberapa lokasi sampel dari dalam negeri. Pengujian yang dilakukan meliputi kadar $\mathrm{CaO}, \mathrm{Si02}, \mathrm{Al} 2 \mathrm{O} 3, \mathrm{Fe} 2 \mathrm{O} 3$, $\mathrm{MgO}$, Moisture dan lainnya.

2. Melakukan pengolahan data dan interpretasi hasil uji agar diketahui karakteristik yang berupa kemurnian dan kualitas batu kapur untuk dapat digunakan dalam pengolahan logam maka dibandingkan dengan beberapa standar yang sering digunakan oleh perusahaan maupun standar yang ada dibeberapa literatur. Nilai standar British Geological Survey(BGS) untuk kemurnian batu kapur seperti pada tabel 1.

Tabel 1. Kemurnian Batu Kapur menurut Standar British Geological Survey (BGS).

\begin{tabular}{|l|c|c|c|c|c|}
\hline $\begin{array}{c}\text { Limestone } \\
\text { classification }\end{array}$ & $\begin{array}{c}\mathrm{CaO} \\
(\mathrm{wt} \%)\end{array}$ & $\begin{array}{c}\mathrm{CaCO}_{3} \\
(\mathrm{wt} \%)\end{array}$ & $\begin{array}{c}\mathrm{MgO} \\
(\mathrm{wt} \%)\end{array}$ & $\begin{array}{c}\mathrm{SiO}_{2} \\
(\mathrm{wt} \%)\end{array}$ & $\begin{array}{c}\mathrm{Fe}_{2} \mathrm{O}_{3} \\
(\mathrm{wt} \%)\end{array}$ \\
\hline $\mathbf{1 0 0 \%}$ limestone & 56.03 & 100.0 & & & \\
\hline Very high purity & $>55.2$ & $>98.5$ & $<0.8$ & $<0.2$ & $<0.05$ \\
\hline High purity & $54.3-55.2$ & $97.0-98.5$ & $<1.0$ & $<0.6$ & $<0.1$ \\
\hline Medium purity & $52.4-54.3$ & $93.5-97.0$ & $<3.0$ & $<1.0$ & $<1.0$ \\
\hline Low purity & $47.6-52.4$ & $85.0-93.5$ & $>3.0$ & $<2.0$ & $>1.0$ \\
\hline Impure & $<47.6$ & $<85.0$ & & $>2.0$ & \\
\hline
\end{tabular}

Standar penggunaan batu kapur menurut pabrik baja didalam negeri dibutuhkan kadar batu kapur dengan : $\mathrm{CaO}>51 \%, \mathrm{Si0}=1,2 \%, \mathrm{Al} 203=0,9 \%$, kadar air < dari 5\%, adapun standar batu kapur yang sebaiknya digunakan juga dikeluarkan oleh standar di India dengan kadar $\mathrm{CaO} \%$, $\mathrm{MgO} \%, \mathrm{SiO} 2 \%$ dan standar dari dalam negeri lainnya seperti yang dikeluarkan literatur 
Kementerian Energi dan Sumberdaya Mineral (ESDM), adapun beberapa standar tersebut seperti pada tabel 2 berikut.

Tabel 2. Standar Kualitas Batu Bahan Baku Kapur

\begin{tabular}{|c|c|c|c|c|}
\hline \multirow[b]{2}{*}{ No. } & \multirow[b]{2}{*}{ Parameter } & \multicolumn{3}{|c|}{ Kadar $(\%)$} \\
\hline & & $\begin{array}{l}\text { Standar Industri } \\
\text { Logam Baja DN }\end{array}$ & Standar Literatur (ESDM) & $\begin{array}{c}\text { Standar } \\
\text { India }\end{array}$ \\
\hline 1. & $\mathrm{CaO}$ & $>51,0$ & $>52$ & $>48$ \\
\hline 2. & $\mathrm{SiO}_{2}$ & $<1,2$ & $<4,0(1,5-4)$ & $<1.5$ \\
\hline 3. & $\mathrm{Al}_{2} \mathrm{O}_{3}$ & $<0,9$ & $\left(\mathrm{Al}_{2} \mathrm{O}_{3}+\mathrm{Fe}_{2} \mathrm{O}_{3}\right)=<3$ & - \\
\hline 4. & $\mathrm{MgO}$ & - & $<3,5$ & $<3$ \\
\hline 5. & $\mathrm{Fe}_{2} \mathrm{O}_{3}$ & - & $<0,65$ & - \\
\hline 6. & $\mathrm{P}$ & - & $<0,10$ & - \\
\hline 7. & Kadar Air & $<5$ & - & - \\
\hline
\end{tabular}

\section{B.2. Pengolahan Data}

Hasil data yang didapatkan dari pengujian akan dilakukan :

1) Interpretasi dengan perbandingan hasil uji dengan standar yang ada misalnya BGS sehingga didapatkan data kualitas bahan baku batu kapur yang diuji.

2) Melakukan pengujian beberapa sampel dan mengumpulkan data sekunder (hasil uji) lainnya serta kompilasi data hasil penelitian batu kapur sebelumnya dibeberapa daerah Indonesia.

\section{HASIL DAN PEMBAHASAN}

Dari hasil uji sampel dan adanya standar yang berlaku maka disini akan dibahas :

\section{C.1. Analisa sampel dan menentukan kemurnian sampel batu kapur berdasarkan dengan standar.}

Pengujian dilakukan terhadap beberapa sampel dari lapangan dan sebagian merupakan hasil kompilasi data sampel serta literatur yang ada. Hasil uji sampel dari beberapa daerah di Indonesia seperti pada tabel 3 berikut .

Tabel. 3 Hasil Analisa Batu Kapur di Beberapa Lokasi Daerah di Dalam Negeri

\begin{tabular}{ccccccccc}
\hline \multirow{2}{*}{ No. } & Lokasi Batu & \multicolumn{7}{c}{$\mathrm{A} \mathrm{n}$ a l i s a $(\%$ Berat $)$} \\
\cline { 3 - 8 } & Kapur & $\mathrm{CaO}$ & $\mathrm{SiO}_{2}$ & $\mathrm{Al}_{2} \mathrm{O}_{3}$ & $\mathrm{MgO}$ & $\mathrm{Fe} 2 \mathrm{O} 3$ & $\mathrm{P}$ & Kadar Air \\
\hline 1 & Jawa Timur 1 & 53,49 & 0,03 & 1,5 & 1,18 & 0,99 & - & - \\
2 & Jawa Barat & 56,20 & 0,10 & 0,50 & 0,20 & 0,10 & - & - \\
3 & Jawa Tengah & 55,51 & 0,13 & 0,12 & 0,23 & 0,06 & - & 0,13 \\
4 & Madura & 41,30 & 0,03 & 5,2 & 26,6 & 0,04 & & \\
5 & Sumbar 1 & 52,60 & 2,12 & 3,77 & 3,86 & ttd & - & - \\
6 & Sumut & 55,00 & 0,32 & 0,11 & 0,30 & - & - & - \\
7 & Kaltim & 50,27 & 1,75 & 1,0 & 0,97 & 0,18 & 0,03 & - \\
8 & Sul-Tra & 51,66 & 1,77 & TT & 1,01 & 1,43 & - & - \\
\hline
\end{tabular}

\section{C.2. Interpretasi hasil pengujian dengan standar untuk industri besi/baja.}

Untuk mengetahui kualitas batu kapur maka dilakukan pengujian lengkap di laboratorium sehingga dapat diketahui kadar kemurnian batu kapur. Penentuan kemurnian dilakukan dengan mengacu kepada standar yang kemurnian sperti standar BGS= (British Geological Survey). Adapun hasil analisa dan kemurnian sampel seperti pada tabel 4 berikut ini. 
Tabel 4. Hasil Uji kualitas Sampel Batu Kapur dan Kemurnian sesuai standar BGS (BGS = British Geological Survey).

\begin{tabular}{|c|c|c|c|c|c|}
\hline \multirow{2}{*}{ Lokasi Sampel } & \multicolumn{4}{|c|}{ Analisa (\% Berat) } & \multirow{2}{*}{ Kemurnian } \\
\hline & $\mathrm{CaO}$ & $\mathrm{MgO}$ & $\mathrm{SiO}_{2}$ & $\mathrm{Fe} 2 \mathrm{O} 3$ & \\
\hline Jawa Timur 1 & 53,49 & 1,18 & 0,03 & 0,99 & Medium \\
\hline Jawa Timur 2 & 44,80 & 0,10 & 1,00 & 1,00 & Tidak \\
\hline Jawa Tengah & 55,51 & 0,23 & 0,13 & 0,06 & Sangat Tinggi \\
\hline Jawa Barat & 56,20 & 0,20 & 0,10 & 0,10 & $100 \%$ batu kapur \\
\hline Sumut & 53,90 & 0,40 & 0,40 & 0,90 & Medium \\
\hline Sumbar 1 & 55,63 & 1,38 & 4,30 & - & Sangat tinggi \\
\hline Kal-Timur & 50,27 & 1,75 & 0,18 & 1,00 & Rendah \\
\hline Kal-Selatan & 46,10 & 0,20 & - & 0,10 & Tidak \\
\hline Sulawesi Barat & 48,66 & 1,92 & - & 1,11 & Rendah \\
\hline Sulawesi Tenggara & 51,66 & 1,77 & 1,43 & - & Rendah \\
\hline Sulawesi Selatan & 54,00 & 0,2 & - & 0,10 & Medium \\
\hline
\end{tabular}

Mengacu kepada standar BGS maka secara umum sampel batu kapur yang dari daerah Sumatera Barat, Jawa Tengah dan Jawa Barat memiliki kemurnian yang tinggi atau masuk kedalam kategori batu kapur yang murni dibandingkan dengan sampel yang lainnya.

Tabel 5. Hasil Uji kualitas Sampel Batu Kapur untuk kebutuhan Industri Besi/Baja.

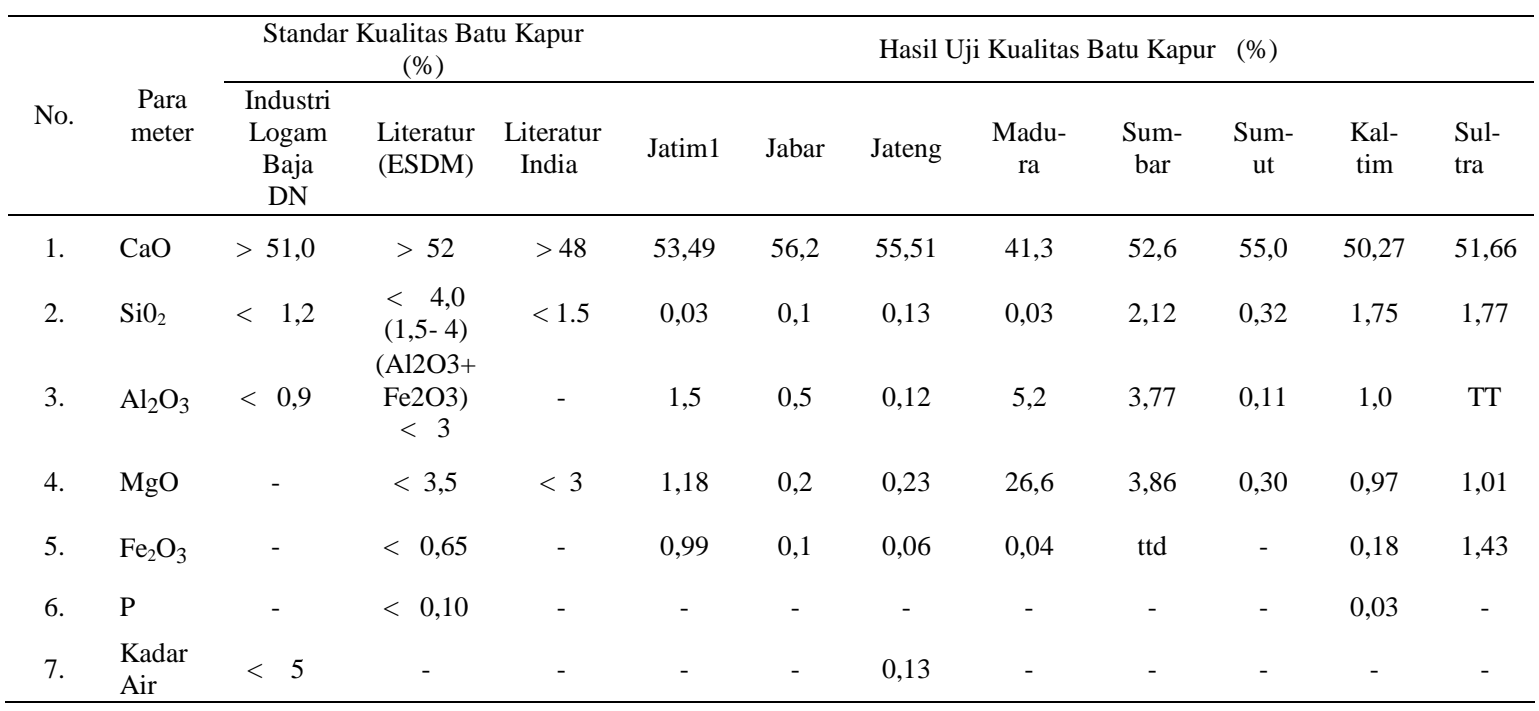

Hasil dari penilaian terhadap sampel Batu kapur yang di uji dan mengacu kepada standar industri besi/baja dapat diketahui bahwa : belum sampel semua umumnya dapat digunakan sebagai bahan baku industri baja/besi. Khusus sampel Jawa Barat, Jawa Tengah, sumut6 dapat digunakan langsung dimanfaatkan oleh industri.

\section{KESIMPULAN}

Secara umum hasil dari penilaian terhadap sampel yang diuji berdasarkan standar BGS maka bahwa semua sampel hampir merupakan batu kapur murni. Untuk pemanfaatan nya lebih lanjut pada industri memang dapat digunakan karena kemurniannya. Sedangkan kualitas sampel dapat diketahui dengan mengacu kepada standar batu kapur : Industri besi/baja dalam negeri, ESDM dan India maka hanya sampel no 2 dari jawa Barat, 3 dari Jawa Tengah dan No.6 dari Sumatera Utara yang memenuhi sebagai bahan baku Industri Besi/baja. Sesuai dengan perkembangan teknologi maka bahan baku Batu Kapur yang ada dapat digunakan oleh industri Besi/baja apabila dilakukan 
pengolahan dan perbaikan komposisi yang dibutuhkan standar. Apalagi sampel yang diuji merupakan masuk kedalam kategori batu kapur dengan kemurnian standar dan untuk memenuhi standar tentunya perlu diperhitungkan biaya karakterisasi dan pengolahannya.

\section{DAFTAR PUSTAKA}

Anonim, 2005, Informasi Mineral dan Batubara, http://www.tekmira.esdm.go.id/data /Batukapur/potensi.asp?xdir=Batukapur\&commId=35\&comm=Batu\%20kapur/gamping, diakses pada 28 Februari 2017.

http://psdg.bgl.esdm.go.id/publikasi khusus/batu gamping/psdg batugamping.html, diunduh 28 Februari 2017.

Hidayat,Wahyu, Sudiyanto,Yanto(2019), Karakteristik dan Sumberdaya Batukapur Di Daerah Sungai Durian Kabupaten Kotabaru Kalimantan Selatan Untuk Kebutuhan Industri Besi Baja, Laporan Penelitian,Serpong, hal-1 -2, PTPSM-BPPT.

Sukhyar,R., dkk, 2014, Batu Gamping di Indonesia, Geologi, Eksplorasi dan pemanfaatan, Pusat Sumberdaya Geologi, Badan Geologi, Kementrian Energi dan Sumber Daya Mineral, Bandung.

Sikumbang,N., dan Heryanto,R., 1994, Peta Geologi Lembar Banjarmasin, Kalimantan, P3G, Bandung.

Heryanto,R., dkk, 1994, Peta Geologi Lembar Sampanahan, Kalimantan, P3G, Bandung.

Batu kapur, https://angghajuner.blogspot.com/2012/01/batu-kapur.html, diunduh 1 agustus 2018.

Clive Mitchel , BGS (2017), High purity limestone assessment : from mine to market, Industrial minerals specialis, BGS London, Notingham UK.p.2- 5.

D,J Harison, BGS (2017),Industrial Minerals laboratori manual, BGS Keyword Notingham UK, p 3-14.

Nur Aulia, Sjahriar,(2017), Uji Kemurnian Komposisi Batu Kapur Tuban Dengan Analisis Rietveld Data Difraksi Sinar-X, laporan, Teknik Fisika ITS, Surabaya. Hal.1-2.

SNI. 0449-2010, “Mutu dan Cara Uji Kapur”, Departemen Perindustrian. 